\title{
DO GIRINO À VOCALIZAÇÃO: ANUROS DA CAATINGA E MATA ATLÂNTICA
}

\author{
MUDANÇAS ONTOGENÉTICAS NA DIETA DE GIRINOS \\ BOKERMANNOHYLA OXENTE (ANURA: HYLIDAE)
}

\author{
Felipe Pereira Alcântara1; Flora Acuña Juncá ${ }^{2}$ \\ 1. Bolsista PROBIC, Graduando em Ciências Biológicas, Universidade Estadual de Feira de Santana, e-mail: \\ fpalcantara10@gmail.com \\ 2. Orientador (a), Departamento de Ciências Biológicas, Universidade Estadual de Feira de Santana, e-mail: \\ florajunc@gmail.com
}

PALAVRAS-CHAVE: Larvas de anuros; Desenvolvimento; Alimentação.

\section{INTRODUÇÃO}

O girino é o estágio larval e não reprodutivo no ciclo de vida bifásico dos anuros (MCDIARMID \& ALTIG, 1999). Girinos são geralmente considerados herbívoros especializados em filtração (DUELLMAN \& TRUEB, 1986) que ingerem material planctônico da coluna d'água, obtendo matéria orgânica a partir de detritos encontrados no ambiente; após a metamorfose esses organismos utilizam principalmente a dieta insetívora. Esta modificação do hábito alimentar se traduz numa grande alteração da morfologia oral dos girinos; devido a essas particularidades morfológicas, os girinos podem explorar recursos que não estão disponíveis aos adultos (DUELLMAN \& TRUEB, 1986; MCDIARMID \& ALTIG, 1999; POUGH, 2008). Os girinos podem ser classificados também como onívoros ou detritívoros oportunistas, e alguns também podem ser canibais oportunistas (podendo se alimentar dos ovos da própria espécie) ou necrófagos (SUMMERS \& AMOS, 1997). Mas ainda não se sabe plenamente sobre quão sortida pode ser a dieta dos girinos.

De maneira geral, os itens alimentares encontrados no trato digestivo dos girinos são algas, protozoários, nematódeos, rotíferos, artrópodes, entre outros. A maioria dos girinos são bentônicos e apresentam a cavidade bucal posicionada na região ventral, se alimentando de perifíton, detritos e folhas de plantas aquáticas (SALTHE \& MECHAM, 1974). De modo que, o conhecimento da dieta das larvas dos anuros é um fator importante para a compreensão da ecologia destes organismos (KUPFERBERG, 1997a).

Este trabalho intenta dar continuidade a um estudo sobre a dieta das larvas dos anfíbios anuros, com a pretensão de estudar a variação ontogenética na dieta dos girinos de Bokermannohyla oxente, (Anura: Hylidae), ao longo de seu desenvolvimento, uma espécie endêmica da Chapada Diamantina, estado da Bahia, Brasil; cruzando resultados e informações de um projeto que descreve a morfologia oral e suas estruturas, também em girinos em diferentes estágios de desenvolvimento. Pretende-se, assim, verificar, a possível variação da dieta em indivíduos da espécie. 


\section{MATERIAL E MÉTODOS}

O material analisado foi coletado durante a execução de trabalhos de campo referentes ao projeto PPBIO, no município de Mucugê e região, estado da Bahia. O material encontrase na Divisão de Anfíbios e Répteis do Museu de Zoologia da Universidade Estadual de Feira de Santana, UEFS. Os girinos de Bokermannohyla oxente foram separados de acordo com a fase de desenvolvimento larval (Gosner, 1960) e divididos em duas categorias de desenvolvimento: fases de 26 a 28 (12 girinos) e fases de 34 a 39 (13 girinos).

Cada girino teve seu comprimento de corpo registrado através de estereomicroscópio com micrométrica acoplada. $\mathrm{O}$ tubo digestório de cada indivíduo foi retirado, medido com o mesmo equipamento citado, e, em uma placa de Petri contendo, aproximadamente, 1.0 $\mathrm{ml}$ de Transeau, foi aberto, lavado e todo o conteúdo liberado armazenado em microtubo. Seguidamente os microtubos foram armazenados à temperatura ambiente. Uma quantidade padronizada da solução citada acima foi direcionada para análises em lâminas (75x24) e lamínulas (50x24) à microscópio óptico, nas oculares de 10x e 40x. Os itens alimentares foram identificados e quantificados quanto à nível genérico com o auxílio de bibliografia específica. Foi calculado um índice de importância alimentar (IA) de cada categoria de item alimentar, a partir da soma da frequência de ocorrência e frequência numérica dividido por 2. Para verificar se houve diferenças na alimentação entre os estágios iniciais e estágios mais avançados, foram feitos uma média e desvio padrão. $\mathrm{O}$ nível de significância foi de 0,05 .

\section{RESULTADOS E DISCUSSÃO}

Foram analisados 25 indivíduos da espécie Bokermannohyla oxente, todos eles coletados na região da Chapada Diamantina, no estado da Bahia. Nota-se claramente o crescimento dos girinos dos estágios mais iniciais, (fases 26 a 28) até os estágios mais próximos aos pré-metamórficos, (fases 34 a 39), (Tabela 1).

Tabela 1. Média e desvio padrão $(\overline{\mathrm{x}} \pm D P)$ dos comprimentos do corpo e intestino, para os 12 girinos nos estágios 26 a 28 e os 13 girinos nos estágios 34 a 39 (Gosner, 1960).

\begin{tabular}{lll}
\hline $\begin{array}{l}\text { Medidas de Tamanho } \\
\text { (Corpo e Intestino) }\end{array}$ & \multicolumn{2}{l}{$\begin{array}{l}\text { Estágios de } \\
\text { Desenvolvimento }\end{array}$} \\
& $\mathbf{2 6 - 2 8}$ & $\mathbf{3 4 - 3 9}$ \\
\hline Comprimento do corpo & $11,31 \pm 1,61$ & $15,11 \pm 1,55$ \\
Comprimento do intestino & $41,41 \pm 11,19$ & $67,15 \pm 18,46$
\end{tabular}

Basicamente a dieta dos girinos foi constituída de nematódeos, algas e matéria orgânica não identificável. Nematódeos tiveram uma maior incidência nos girinos que se encontravam nos estágios pré-metamórficos, chegando a uma aproximação numérica com 
a importância alimentar das Diatomáceas e Cosmarium, da mesma forma que as algas Closterium, tiveram um aumento significativo em relação ao grupo 1 de desenvolvimento (fases 26 a 28), (tabela 1). Duas possibilidades podem explicar esse maior consumo: $1^{\text {a }}$ ) a partir do desenvolvimento dos indivíduos, aumentou a capacidade destes de se alimentarem de nematódeos; $2^{a}$ ) uma vez que não foi possível uma identificação mais precisa destes espécimes de Nemátodas, há a possibilidade de que parte ou todos os nematódeos encontrados sejam parasitas. Neste estudo, serão considerados como parte da dieta.

Algas apresentaram a maior diversidade e número na dieta destes indivíduos. Foram observadas em maior abundância as Diatomáceas e o gênero Cosmarium, (Tabela 2).

Diatomáceas são algas comumente encontradas nos ambientes aquáticos e na dieta de girinos de muitas espécies (BRANDINI, 1985; MENEZES, 1989; SASSI, 1991). Assim, possivelmente, os girinos ingeriram essas algas pela grande disponibilidade no meio, consumindo-as de maneira aleatória juntamente com os outros itens alimentares.

Tabela 2. Frequência relativa (\%) dos itens alimentares especificados encontrados nas dietas dos girinos nos estágios 26 a 28 (12 indivíduos) e nos estágios 34 a 39 (13 indivíduos) (Gosner, 1960).

\begin{tabular}{|c|c|c|c|c|}
\hline \multirow[t]{3}{*}{ Itens Alimentares } & \multicolumn{4}{|c|}{$\begin{array}{l}\text { Estágios de } \\
\text { Desenvolvimento }\end{array}$} \\
\hline & $26-28$ & & $34-39$ & \\
\hline & FN\% & IA & FN\% & IA \\
\hline Diatomácea & 40,75 & 70,37 & 35,56 & 67,78 \\
\hline Cosmarium & 36,62 & 68,31 & 32,05 & 66,02 \\
\hline Euglena & 7,12 & 53,56 & 6,75 & 49,52 \\
\hline Scenedesmus & 2,24 & 46,95 & 7,02 & 49,66 \\
\hline Algas verdes & 1,96 & 38,48 & 3,24 & 40,08 \\
\hline Micrasteria & 2,58 & 38,79 & 4,05 & 48,17 \\
\hline Matéria orgânica & 6,28 & 53,14 & 6,54 & 53,27 \\
\hline Nematódeos & 0,45 & 25,22 & 3,67 & 51,83 \\
\hline Closterium & 0 & 0 & 1,08 & 27,46 \\
\hline
\end{tabular}

\section{CONCLUSÃO}

Através dos estudos realizados durante esta pesquisa, no seu fechamento, foi possível perceber que houve diferenças significativas entre as dietas do grupo 1 (girinos nas fases 26 a 28 de desenvolvimento) em comparação ao grupo 2 (girinos nas fases 34 a 39 de desenvolvimento).

\section{REFERÊNCIAS BIBLIOGRÁFICAS}

BRANDINI, F.P. Seasonal succession of phytoplankton in the Bay of Paranaguá (Paranaguá, Brazil). Revista Brasileira de Biologia, v. 45, n.4, p. 687-694, 1985. 
DUELLMAN, W.E. \& TRUEB, L. 1986. Biology of amphibians. McGraw-Hill, New York.

GOSNER, K. L. A simplified table for staging anura embryos and larvae, with notes on identification. Herpetologica, v.18, p.183-190, 1960.

KUPFERBERG, S.J. 1997a. The role of larval diet in anuran metamorphosis. American Zoology 37 (2): 146-159.

MCDIARMID, R.W.; ALTIG, R. (Ed.). Tadpoles: the biology of anuran larvae. University of Chicago Press, 1999.

MENEZES, M. Contribuição ao conhecimento das algas do gênero Euglena (Euglenophyceae) no município do Rio de Janeiro e Arredores, Brasil. Acta. Bot. Bras. V.3, n.1, 1989.

POUGH, H. F.; JANIS, C. M.; HEISER, J. B. A vida dos vertebrados. $4^{\text {a }}$ ed. São Paulo: Atheneu, 2008. 684p.

SALTHE, S. N. \& MECHAM, J. S. (1974). In Physiology of the Amphibia, Vol. 2. (B. Lofts, ed.). p. 309-521. New York: Academic Press.

SASSI, R. Phytoplankton and environmental factors in the Paraíba do Norte River estuary, northeastern Brazil: composition, distribution and quantitative remarks. Bolm. Inst. Oceanografia, v. 39, n.2, p. 93-115, 1991.

SUMMERS K, AMOS W, 1997. Behavioral, ecological and molecular genetic analyses of reproductive strategies in the Amazonian dart-poison frog Dendrobates ventrimaculatus. Behav. Ecol. 8: 260-267. 